\title{
Ranking of Leagility Factors Based on Job Satisfaction through a Combinatory Model of Fuzzy TOPSIS and AHP (Case Study: M.R.I Hospital, Shiraz, Iran)
}

\author{
Hasan Dehghan Denavi ${ }^{*}$, Mohammad Mirabi², Afarin Rezaei ${ }^{3}$ \\ ${ }^{1}$ Department of Industrial Management, Yazd Branch, Islamic Azad University, Yazd, Iran \\ ${ }^{2}$ Industrial Engineering Group, Ayatollah Haeri University of Meybod, Meybod, Iran \\ ${ }^{3}$ Department of Industrial Management, Yazd Branch, Islamic Azad University, Yazd, Iran \\ Email: *H.dehghan@iauyazd.ac.ir
}

How to cite this paper: Denavi, H.D., Mirabi, M. and Rezaei, A. (2018) Ranking of Leagility Factors Based on Job Satisfaction through a Combinatory Model of Fuzzy TOPSIS and AHP (Case Study: M.R.I Hospital, Shiraz, Iran). Open Journal of Business and Management, 6, 21-38.

https://doi.org/10.4236/ojbm.2018.61002

Received: September 28, 2017

Accepted: December 8, 2017

Published: December 11, 2017

Copyright $\odot 2018$ by authors and Scientific Research Publishing Inc. This work is licensed under the Creative Commons Attribution International License (CC BY 4.0).

http://creativecommons.org/licenses/by/4.0/

\begin{abstract}
The main purpose of this study is to identify and rank leagility factors based on job satisfaction in the M.R.I Hospital, Shiraz, Iran. From the purpose point of view, this research is an applied research. In this research two methods of fuzzy tops are the Analytical Hierarchy Process (AHP) to compute the inconsistency rate, and rank the job satisfaction criteria AHP is employed; afterwards the fuzzy TOPSIS is used to rank the lean-agile criterions. In all the committed pairwise comparisons the consistency rate has scored less than 0.1 and ranking has been carried out. Results obtained from this research indicate ranking of the criteria, and also reveal the importance of the organizational factors with the most weight (0.686), and then the environmental factors with a weight of 0.126 and finally factors associated with nature of work with a weight of 0.098 . Moreover result of fuzzy TOPSIS demonstrates that, having the highest closeness coefficient, providing high quality services has the highest priority among the criteria. The importance of other criteria is as follows: on time services, competency, responsiveness, flexibility, speed, and waste reduction. It can be a benchmarking for researches and decision makers to apply the results of this research.
\end{abstract}

\section{Keywords}

Lean, Agility, Job Satisfaction, Organization

\section{Introduction}

Human resources are regarded as the most important capital in an organization and in order to have a dynamic organization, having undertaking people, and 
for realization and execution of the organization goals, there is a need to have motivated interested-to-work employees. Given the differences among human individuals in different areas, job and fulfillment of job duties are the most important source of satisfaction for some of the people. If-due to any reason-this satisfaction goes missing, its undesirable consequences will embroil organization to a challenge. Hence, one of the most important motivation factors in work settings is the job satisfaction that inscribes a set of desirable or undesirable feelings toward a job [1]. Some regard job satisfaction as a holistic satisfaction in most of the particular job conditions, including pay, promotion, security, etc. Behaviors of the colleagues and superiors are among the most critical factors in securing job satisfaction. Management styles, relationships, and rewards influence the attitude and performance of the employees as well [2].

Organization agility on the other hand, has been introduced as one of the effective variables and factors on job satisfaction [3] which could be defined as: a complicated multi-dimensional concept [4] that includes the ability to feel environmental changes as well as swift responsiveness to unpredictable changes [5]. Lean service providing is also among the effective factors on job satisfaction that leads to satisfaction through lower waste and higher quality as well as on time services. Due to their important obligations in disease prevention, healthcare, and treatment of diseases, health and therapy organizations have a peculiar position and dissatisfaction of the employees of therapy centers lead to low quality service providing and ultimately causes dissatisfaction in the ill people. Attending their ideas and demands is in fact paying attention to people health [6]. Thereupon, given that paying attention to higher job satisfaction of hospital employees leads to higher quality of services and, consequently, higher satisfaction of patients, this research studies the effect of leanness and agility as the effective factors on job satisfaction. Employees' job satisfaction is important because it increases productivity and improves working spirit and organizational commitment. What is observed in today's organizations suggests that employees are not quite satisfied with the environments they work in. However, agility and leanness of the organization does affect job satisfaction and attitudes of employees [3]. In the present study, different dimensions of organizational agility (responsiveness, competence, flexibility and rapidity) and dimensions of organizational leanness (provision of high-quality services, reduction of losses and timely services) were combined and the relationship between them and their effect on job satisfaction (organizational factors, environmental factors and nature of the job) were studied which is of great significance. Therefore, the main question research is as follows:

Which of the leanness-agility factors has the most effect on job satisfaction?

Going forward, the literature, methodology, data analysis and finally discussion and conclusion will be presented.

\section{Literature Review}

This section is concerned with expression of the concepts agility, leanness, and 
employees' job satisfaction as well as research works conducted in the past, expressed in form of theoretical framework.

\subsection{Definitions and Concepts}

This section tries to provide the reader with those definitions relative to the research variables as organization leanness, organization agility, and employees' job satisfaction. Job satisfaction: Researchers have presented different definitions of satisfaction. Some define job satisfaction as a mind phenomenon which is a result of synchronization between attitude and behavior [7]. Dawal et al. (2009) state that job satisfaction is degree of happiness and joy which an individual has toward their job [8]. Lean system focuses on cost reduction by eliminating non-value added activities, so that several advantages can be obtained such as minimization/elimination of waste, increased business opportunities and high competitive advantage. Lean manufacturing is adopted where there is a stable demand and to ensure a level schedule [9]. During the last two decades, agility has been a key concept, having many of researchers discussing and giving ideas about it [10]. Narasimhan et al. (2006) considers agility as the ability of effective and efficient change of the operational status in response and reaction to the uncertain and changing market conditions [11].

The concepts of leanness and agility have gained significant importance in recent decades. For successful survival in worldwide market competition, industrial segment in all over the world have updated their current business strategies by adapting to these concepts in order of gaining competitive advantages. The concept of Leagility is a combination of outstanding features of "leanness and agility". In this period of globalization, modern manufacturing companies are continuously, faced with increased market competition. Significant industrial growth in recent decades accompanied by birth of modern concepts of leanness; agility and recently Leagility have completely revolutionized their traditional manufacturing strategies. These brand new strategies empower the companies to survive in the turbulent atmosphere of violent competition created by their competitors. Recent developments have shown that the principle of Leagility has a significant potential in fighting off the complexities present in market trends. Therefore, today the Leagility principles have attracted the manufacturing companies and researchers whose objective is finding out the outstanding advantages of Leagility principle in different industrial sections [9].

Agility can be defined as the ability of an organization in responding to market change and customer demand. One of the objectives of the agile organization is satisfying customers and employees. Organizational agility, have been claimed to be one of the main factors of establishing job satisfaction in recent years [3]. There are several sources which, emphasis the positive influences of operationalizing the principles of leanness on job satisfaction [12]. Lean making in a proactive action with positive influences on efficiency and satisfaction [13] (Hafey, 2009) and provides opportunities for the company which end up in job satisfac- 
tion [14] (Holden, 2011). Therefore, it can be concluded that using lean tools in organization while result in lower wastes and costs accompanied by value creation, which will end up in employee job satisfaction. There are several evidences that show operationalizing lean techniques will have direct and indirect positive effects on job satisfaction [15]. Since Leagility can simplify service providing and responsiveness by creating synergy in improving processes, the result of implementing it in work environment will be improvement in employee satisfaction. Therefore, the objective of this study is evaluating the job satisfaction of MRI hospital's employees.

\subsection{Previous Research}

Different researchers have worked on lean, agile, and lean agile systems. Some of the relative available sources in use are as follows:

Regarding the lean system, has provided a model, which is in fact the improved model of Wills [16]. In this improved dimensional analysis, in order of increasing the accuracy of system leanness, a method has been proposed that considers the importance and weight of individuals' words in scoring according the level of their competency and experience. Moreover, the scores given to individual criteria by each person were included in the formula. Arnolet Poll (2010) has shown the value of lean approach and the influence of these criterions in production improvement [17].

In a research under the title "investigation of the concept and application of agility in the service section of University of Esfahan, Esfahan, Iran", Shahin and Lellahgani (2011), come to the conclusion that application of the principles of agility (speed, flexibility, responsiveness, and competency) has a significant effect on the diversity of the provided services by universities and the component flexibility is known as the most important factor for university agilization [18].

Related to Leagility paradigm, Guimaraesand Carvalho (2012), in a study, in addition of reviewing the leanness and agility paradigms have examined leagility in a healthcare center. The results of the study show that leagility paradigm by creating balance between cost and quality increase flexibility and response rate [19]. Matawale et al. (2013) in a study titled "Development of a decision support system for leagility assessment in fuzzy environment" have worked on leagility field. They evaluated leagility by fuzzy logic in a case study [9].

Regarding job satisfaction and leanness in a comprehensive study in two manufacturing Polish company, De Haan et al. (2008), have analyzed the attributes of JC model, and have examined the characteristics of JCM model and examined the applying method of "Lean" actions. Introducing "Lean" actions has resulted in higher job satisfaction of the workers [20]. Hafey (2009) has proven that leanness tools such as Kyzen are useful in safety, health and satisfaction of the employees and bring about higher efficiency in the inside and outside of the organization, all of which result in satisfaction [13]. The results of a survey conducted by Morse (2014) show that job satisfaction in employees could be a 
product of operationalizing leanness principle.

St John et al. (2001) claim that heavy competition among organizations and the acceleration of technological change and social changes emphasis the speed component. Therefore, it can be claimed that organizations with higher sensitivity, able to understand change rapidly and highly reactive to these changes, have more basis for satisfying their employees and are more successful in this regard [21]. The findings of Nickpourand Salajegheh (2010), showing a significant relationship between organizational agility and job satisfaction were confirmed [3].

\subsection{Theoretical Framework}

Results of this research indicate that the lean agility approach is one of the factors influencing job satisfaction. In fact, the part which is most in touch with customers benefits the agile thought and the part most in touch with manufacture benefits from lean thought. Independent variables include agility-with sub-variables like response time, competency, flexibility-and leanness with sub-variables like higher quality service providing, waste reduction, in time services, etc. Since there are a lot of service applications for a hospital and providing high quality, on time and quick services is of much importance, and given that job satisfaction could have a critical impact in realization of such thing, this research studies two combinatory factors influencing job satisfaction.

Combining the dimensions of the organizational agility-including responsiveness, competency, flexibility, and speed with [22] [23] [24] — dimensions of the organizational leanness-including higher quality service providing, waste reduction, on time service [9] [16] [17] — their relationship with an effect on job satisfaction-including organizational factors, environmental factors, and job essence [25] - is investigated. The relationship between job satisfaction and agility [3] [21], subjects relative to leagility [9] [19], and the relationship between leanness and job satisfaction [12] [13] [14] [15] [20] [26] are also considered. As a result, this research evaluates the effect of independent variables (leanness, agility, and the combination leagility) on dependent variable (job satisfaction) of the M.R.I Hospital employees, Shiraz, Iran. Furthermore, the relationship between independent variables is also studied. Thereupon, considering the aforementioned matters, the research conceptual model is shown in Figure 1.

\section{Research Method}

This research is an applied research from the purpose point of view and a descriptive-correlation study in essence and methodology. The statistical population consists of 80 people and the sample contains 65. In the present study, Cochran's formula and Morgan's table have been used for sampling. Given that the statistical population of this study is composed of 80 individuals, thus, $\mathrm{n}=66$ according to the Cochran's formula. This research will be firstly concerned with validity and reliability determination. In order to determine the reliability of the questionnaire used in the study, Cronbach's alpha has been used. The face 


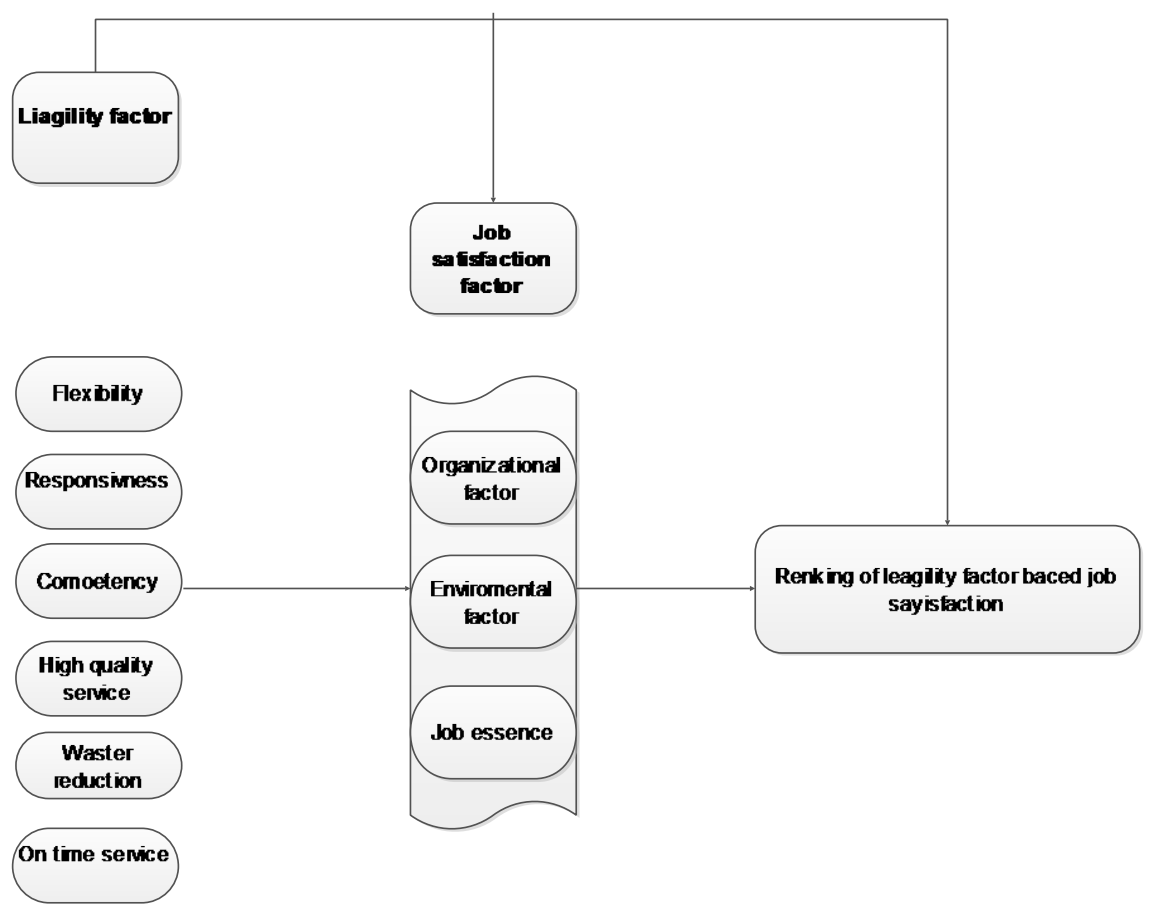

Figure 1. Aconeptual model of the research.

validity of the questionnaire has also been measured in this research; in such a way that the researchers asked scholars and experts in the field of the study about their opinion about the accuracy and clarity of the questions in the questionnaire. According to the opinions of relevant professors and experts, the questionnaire used in this study is valid. To select the appropriate statistical method, first normality of variables is investigated. Eventually, using fuzzy TOPSIS, the leagility factors were ranked according to the indices of job satisfaction.

\section{Data Analysis}

Using fuzzy TOPSIS In this section, the leagility factors are ranked according to the indices of job satisfaction (Figure 2).

\subsection{Fuzzy Topsis Algorithm}

The fuzzy theory was introduced by Zadeh (1965) as an extension of the classical notion of set. Among the various shapes of fuzzy number, triangular fuzzy number (TFN) is the most popular one. TFN is a fuzzy number represented with three points as follows:

$\tilde{A}=(l, m, u)$ which can be drawn in Figure 1 . This representation is interpreted as membership functions and holds the following conditions:

The TOPSIS (technique for order preference by similarity to an ideal solution) was first developed by Hwang and Yoon (1981). In this method two artificial alternatives are defined as positive-ideal and negative-ideal solution. The positive-ideal solution is a solution that maximizes the benefit criteria and minimizes 


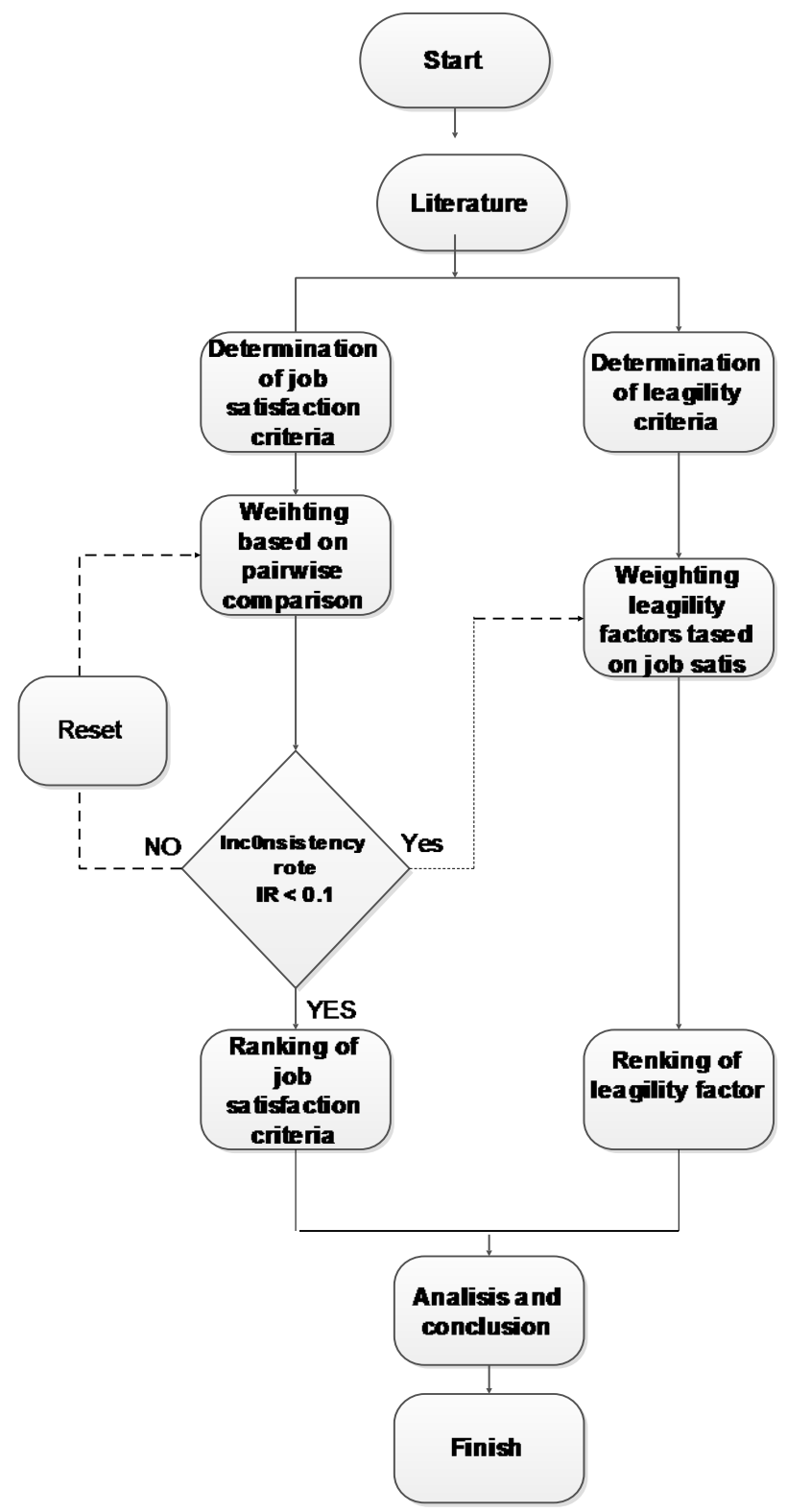

Figure 2. The extended model for the effect of leagility on job satisfaction.

the cost criteria, whereas the negative ideal solution maximizes the cost criteria and minimizes the benefit criteria. In short, the positive-ideal solution is the one which has the best level for all attributes considered, whereas the negative ideal solution is the one which has the worst attribute values. TOPSIS selects the alternative that is the closest to the positive ideal solution and farthest from negative ideal solution. The steps of fuzzy TOPSIS algorithm can be constructed in details as follows [27] (Figure 3).
a) $I$ to $m$ is increasing function
b) $m$ to $u$ is decreasing function
c) $l \leq m \leq u$ 


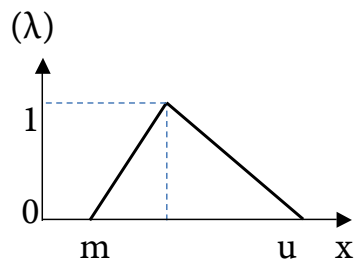

Figure 3. Triangular fuzzy number.

$$
\mu_{A}(X)= \begin{cases}0 & \text { for } X<l ; x \\ \frac{x-1}{m-1} & \text { for } \leq x \leq m \\ \frac{u-x}{u-m} & \text { for } \leq x \leq u\end{cases}
$$

Step 1: assume that $x_{i j}^{k}$ shows value of alternative $i$. In a group consists of $K$ decision makers, criteria values of alternatives calculated as $\left(x_{i j}=\left(a_{i j}, b_{i j}, c_{i j}\right)\right)$ :

$$
x_{i j}^{k}=\left[x_{i j}^{1}+x_{i j}^{2}+\cdots+x_{i j}^{k}\right] \frac{1}{k}
$$

Step 2: Assume that $w_{i j}^{k}$ shows weight of importance critia $j$. In a group consists of $K$ decision makers, importance weight critia calculated as as $\left(w_{i j}=\left(a_{i j}, b_{i j}, c_{i j}\right)\right)$ :

$$
w_{i j}^{k}=\left[x_{i j}^{1}+x_{i j}^{2}+\cdots+x_{i j}^{k}\right] \frac{1}{k}
$$

In a multi critia decision making problem decision and weight matrices as blow m: number of alternatives, $n$ : number of critia):

$$
D=\left[\begin{array}{cccc}
x_{11} & x_{12} & \cdots & x_{1 n} \\
x_{1 n} & x_{22} & \cdots & x_{2 n} \\
\cdots & \cdots & \cdots & \cdots \\
x_{m n} & \cdots & \cdots & x_{m n}
\end{array}\right] ; W=\left[w_{1}, w_{2}, \cdots, w_{n}\right]
$$

Steep 3: Normalization of decision matrix can be computed with two ways according to benefit or cost criteria.

$$
\begin{aligned}
& r_{i j}=\left(\frac{a_{i j}}{c_{j}^{*}}, \frac{b_{i j}}{c_{j}^{*}}, \frac{c_{i j}}{c_{j}^{*}}\right), j \in B, c_{j}^{*}={ }_{i}^{\max } c_{i j} \\
& r_{i j}=\left(\frac{a_{j}^{-}}{c_{j}^{*}}, \frac{a_{j}^{-}}{c_{j}^{*}}, \frac{a_{j}^{-}}{c_{j}^{*}}\right), j \in B, a_{j}^{-}={ }_{i}^{\max } a_{i j}
\end{aligned}
$$

Hereby, $c_{j}^{*}$ is maximum value of fuzzy numbers' third parameters in a column, $a_{j}^{*}$

Is minimum value of fuzzy numbers' first parameters in a column.

Step 4: Normalized with weights of decision makers' preference decision matrix as below, calculated fizzy numbers in $[0,1]$ interval

$$
v_{i j}=r_{i j} \times w_{i j}
$$




$$
\begin{aligned}
& A^{*}=\left(v_{1}^{*}, v_{2}^{*}, \cdots, v_{n}^{*}\right) \\
& A^{-}=\left(v_{1}^{-}, v_{2}^{-}, \cdots, v_{n}^{-}\right)
\end{aligned}
$$

Step 5: Fuzzy positive ideal solution is defined as $A^{*}=\left(v_{1}^{*}, v_{2}^{*}, \cdots, v_{n}^{*}\right)$ and similarly, fuzzy negative ideal solution is defined as $A^{-}=\left(v_{1}^{-}, v_{2}^{-}, \cdots, v_{n}^{-}\right)$. Hereby, $v_{j}^{*}$ and, $v_{j}^{-}$equal $(1,1,1)$ and $(0,0,0)$ respectively. There are same numbers of criteria, $(1,1,1)$ and $(0,0,0)$. Distances of alternatives to positive and negative solutions as below:

$$
\begin{aligned}
d_{i}^{*} & =\sum_{i=1}^{n} d\left(v_{i j}, v_{j}^{*}\right), i=1,2, \cdots, m \\
d_{i}^{-} & =\sum_{i=1}^{n} d\left(v_{i j}, v_{j}^{-}\right), i=1,2, \cdots, m
\end{aligned}
$$

Distance between two fuzzy numbers can be calculated as below:

$$
d(a, b)=\sqrt{\frac{1}{3}}\left[\left(a_{1}-b_{1}\right)^{2}+\left(a_{2}-b_{2}\right)^{2}+\left(a_{3}-b_{3}\right)^{2}\right]
$$

Step 6: Using calculated distance coefficients is made a ranking. The biggest distance coefficient is selected as best alternative [28].

$$
\text { CC } i=\frac{d_{t}^{-}}{d_{i}^{+}+d_{t}^{-}}
$$

\subsubsection{AHP}

Firstly in this stage, the AHP technique is employed to acquire the inconsistency rate and rank the job satisfaction indices. Thereafter, the fuzzy TOPSIS technique is applied for ranking the leagility criteria. In analysis of the questionnaires, the inconsistency rate of all pairwise comparisons is calculated. Subsequently, those questionnaires with inconsistency rates less than 0.1 are chosen for criteria ranking. Subsequently, employing the Expert Choice software, questionnaires are aggregated using geometric mean. Results are given in the pairwise comparison matrix of Figures 4-6 reveal ranking of the job satisfaction criteria.

Results of criteria ranking in form of a bar chart are shown in Figure 6.

Results indicate a consistency rate of less than 0.1 for the criteria. Ranking of the criteria also reveals the importance of the organizational factors with the most weight (0.686), and then the environmental factors with a weight of 0.126 and finally factors associated with job essence with a weight of 0.098 .

\subsubsection{Ranking by TOPSIS}

In the questionnaire of TOPSIS, the linguistic terms very low, low, average, high, and very high are used. These form the data for decision matrix of fuzzy TOPSIS. To analyze, there is a need to translate linguistic terms according to a conventional scale, shown in Table 1.

Step 1) Development of a decision matrix to rank $m$ alternatives and $n$ criteria

The decision matrix is shown in Table 2. First, all the linguistic terms are turned to fuzzy triangular numbers. Thereafter, ideas of all people are 


\begin{tabular}{|l|l|r|r|}
\hline \hline & Organizational & Environmental & Nature of Work \\
\hline Organizational & & 3.48182 & 6.38958 \\
\hline Environmental & & & 2.41369 \\
\hline Nature of Work & Incon: 0.01 & & \\
\hline
\end{tabular}

Figure 4. Aggregation of the questionnaires applying geometric mean (software output).

Combined instance - Sythesis with respect to: Goal: Ranking

Overall Inconsistency $=0.01$

Organizational $\mathbf{0 . 6 8 6}$

Environmental $\mathbf{0 . 2 1 6}$

Nature of Work 0.098

Figure 5. Ranking of the job satisfaction criteria (software output).

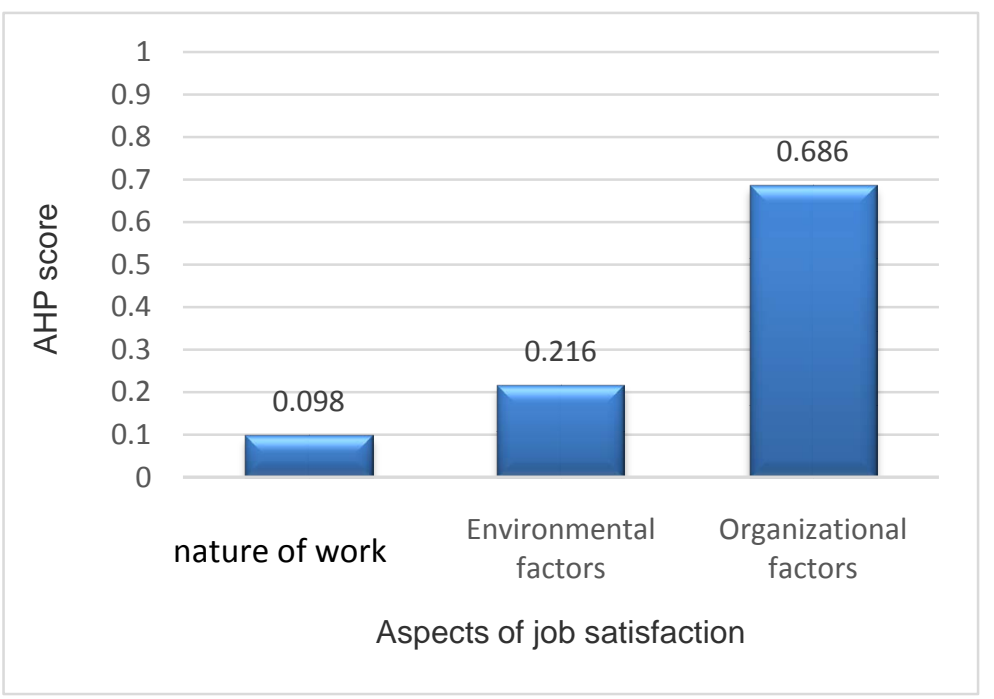

Figure 6. Ranking of the job satisfaction criteria using AHP.

Table 1. Linguistic terms and their equivalents.

\begin{tabular}{cc}
\hline Linguistic terms & Fuzzy triangular numbers \\
\hline Very low & $(0 ، 0 / 1 ، 0 / 3)$ \\
Low & $(0 / 1 ، 0 / 3 ، 0 / 5)$ \\
Average & $(0 / 3 ، 0 / 5 ، 0 / 7)$ \\
High & $(0 / 5 ، 0 / 7 ، 0 / 9)$ \\
Very high & $(0 / 7 ، 0 / 9 ، 1)$
\end{tabular}

aggregated. Ultimately, the decision matrix that is the result of a consensus between all people (number of experts: 7) is demonstrated in Table 2.

Step 2) Development of the fuzzy weighted normalized matrix

With the assistance of the following relations, the normalized decision matrix (R) is acquired. According to (EQ5), in which B and C represent the positive and negative sets of criteria respectively. Afterwards, multiplying the normalized 
Table 2. Fuzzy decision matrix data.

\begin{tabular}{cccc}
\hline & Job nature & Environmental factors & Organizational factors \\
\hline Responsiveness & $(0.46,0.66,0.86)$ & $(0.38,0.58,0.78)$ & $(0.38,0.58,0.78)$ \\
Competency & $(0.42,0.62,0.82)$ & $(0.38,0.58,0.82)$ & $(0.42,0.62,0.82)$ \\
Flexibility & $(0.34,0.54,0.74)$ & $(0.34,0.54,0.86)$ & $(0.46,0.66,0.86)$ \\
Speed & $(0.34,0.54,0.74)$ & $(0.34,0.54,0.82)$ & $(0.42,0.62,0.82)$ \\
Higt-quality services & $(0.42,0.62,0.82)$ & $(0.46,0.66,0.84)$ & $(0.46,0.66,0.84)$ \\
Waste Reduction & $(0.38,0.58,0.78)$ & $(0.34,0.54,0.78)$ & $(0.38,0.58,0.78)$ \\
In-time services & $(0.38,0.58,0.78)$ & $(0.42,0.62,0.84)$ & $(0.46,0.66,0.84)$ \\
\hline
\end{tabular}

decision matrix $\left(\tilde{r}_{i j}\right)$ by the fuzzy weights of the criteria $(\tilde{W})$, the fuzzy weighted normalized decision matrix is obtained ( $\tilde{V}$ ) (EQ6). Results are shown in Table 3.

$$
\begin{aligned}
& \tilde{V}_{i j}=\tilde{r}_{i j} \otimes \tilde{W}_{j} \\
& \tilde{V}=\left[\tilde{V}_{i j}\right]_{m \times n}, i=1,2 \cdots, m, j=1,2 \cdots, n
\end{aligned}
$$

Step 3) Determination of a positive ideal solution $\left(\tilde{V}_{j}^{*}\right)$ and a negative ideal solution $\left(\tilde{V}_{j}^{-}\right)$(EQ1)

In which $B$ and $C$ respectively represent the positive and negative set of criteria. In Table 4, the positive ideal solution and the negative ideal solution are shown for each criterion.

Distance between each alternative and the positive $\left(d_{i}^{*}\right)$ as well as the negative $\left(d_{i}^{-}\right)$ideals.

If the fuzzy positive ideal solution is assumed $A^{*}$ and the fuzzy negative ideal is assumed $A^{-}$, the distance between each alternative and $A^{*}$ is called the positive distance, and the distance between each alternative and $A^{-}$is called the negative distance. Both the distances are obtained from the following formula (EQ7).

As the distance between two fuzzy triangular numbers $\tilde{M}=\left(m_{1}, m_{2}, m_{3}\right)$ and $\tilde{N}=\left(n_{1}, n_{2}, n_{3}\right)$ is determined through the relationship (EQ 8).

Table 5 calculates the distance between each alternative from the positive ideal solution.

Table 6 calculates the distance each alternative and the negative ideal solution.

Step 4) Determination of the closeness coefficient $\left(C C_{i}\right)$ for each alternative

After the positive distance $\left(d_{i}^{+}\right)$and the negative distance $\left(d_{i}^{-}\right)$for each alternative $A_{i}$, the closeness coefficient is calculated(EQ9).

Table 7 reveals closeness coefficients for each alternative. The alternative with higher CC has the higher priority. Figure 7 depicts the ranking of alternatives.

Results of fuzzy TOPSIS demonstrates that, having the highest CC-, providing high quality services has the highest priority among the criteria. The importance of other criteria is as follows: on time services, competency, responsiveness, flexibility, speed, and waste reduction. 
Table 3. Development of the fuzzy weighted normalized matrix.

\begin{tabular}{cccc}
\hline & Job nature & Environmental factors & Organizational factors \\
\hline Responsiveness & $(0.53,0.77,1)$ & $(0.44,0.67,0.91)$ & $(0.44,0.67,0.91)$ \\
Competency & $(0.49,0.72,0.95)$ & $(0.44,0.67,0.95)$ & $(0.49,0.72,0.95)$ \\
Flexibility & $(0.4,0.63,0.86)$ & $(0.4,0.63,1)$ & $(0.53,0.77,1)$ \\
Speed & $(0.4,0.63,0.86)$ & $(0.4,0.63,0.95)$ & $(0.49,0.72,0.95)$ \\
Quality services & $(0.49,0.72,0.95)$ & $(0.53,0.77,0.98)$ & $(0.53,0.77,0.98)$ \\
Waste Reduction & $(0.44,0.67,0.91)$ & $(0.4,0.63,0.91)$ & $(0.44,0.67,0.91)$ \\
In-time services & $(0.44,0.67,0.91)$ & $(0.49,0.72,0.98)$ & $(0.53,0.77,0.98)$ \\
\hline
\end{tabular}

Table 4. The positive and negative ideal solutions.

\begin{tabular}{lcc} 
& The positive ideal solution $\tilde{V}_{j}^{*}$ & The negative ideal solution $\tilde{V}_{j}^{-}$ \\
\hline Criterion 1 & $(1,1,1)$ & $(0.4,0.4,0.4)$ \\
Criterion 2 & $(1,1,1)$ & $(0.4,0.4,0.4)$ \\
Criterion 3 & $(1,1,1)$ & $(0.44,0.44,0.44)$ \\
\hline
\end{tabular}

Table 5. The distance between each alternative and the positive ideal solution.

\begin{tabular}{cc}
\hline & $\left(d_{i}^{*}\right)$ \\
\hline Responsiveness & 1.054045 \\
Competency & 1.049113 \\
Flexibility & 1.127875 \\
Speed & 1.166065 \\
High quality services & 0.938606 \\
Waste reduction & 1.167218 \\
On time services & 1.014179 \\
\hline
\end{tabular}

Table 6. The distance between each alternative and the negative ideal solution.

\begin{tabular}{cc}
\hline & $\left(d_{i}^{-}\right)$ \\
\hline Responsiveness & 1.055517 \\
Competency & 1.075727 \\
Flexibility & 1.051164 \\
Speed & 0.98687 \\
High quality services & 1.14899 \\
Waste reduction & 0.962247 \\
On time services & 1.091486 \\
\hline
\end{tabular}

Table 7. Closeness coefficients of alternatives.

\begin{tabular}{cccc}
\hline & $\left(d_{i}^{-}\right)$ & $\left(d_{i}^{*}\right)$ & $\left(C C_{i}\right)$ \\
\hline Responsiveness & 1.055517 & 1.054045 & 0.5003 \\
Competency & 1.075727 & 1.049113 & 0.5063 \\
Flexibility & 1.051164 & 1.127875 & 0.4824 \\
Speed & 0.98687 & 1.166065 & 0.4584 \\
High quality services & 1.14899 & 0.938606 & 0.5504 \\
Waste reduction & 0.962247 & 1.167218 & 0.4519 \\
On time services & 1.091486 & 1.014179 & 0.5184 \\
\hline
\end{tabular}




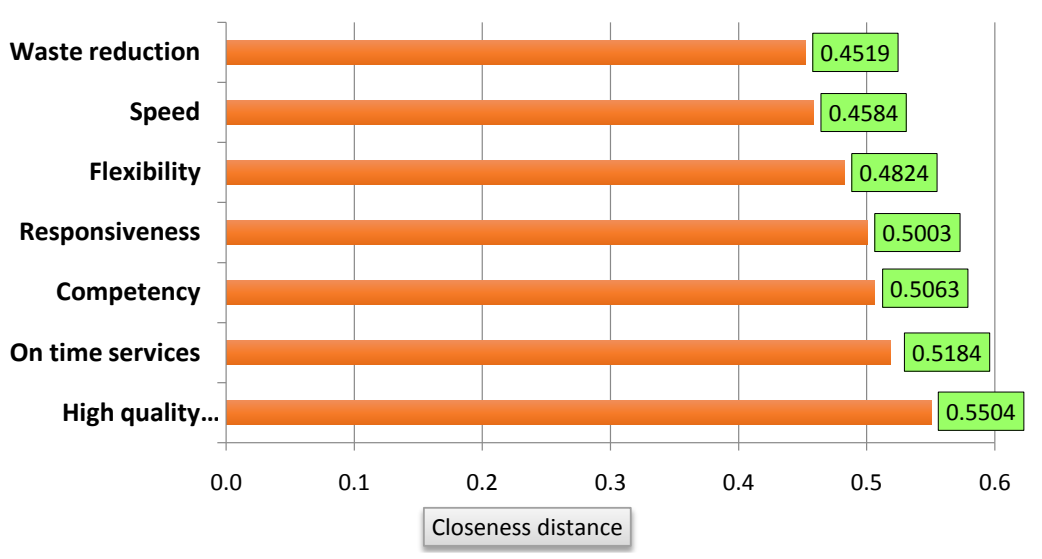

Figure 7. Ranking of the alternatives according to the closeness coefficient.

\section{Discussion}

The results obtained from this study regarding the effect of leanness of the job on the job satisfaction of the employees are similar to the findings of many other studies and indicate that it does have a great impact on job satisfaction. In an inclusive study conducted in two productive companies in Netherland, i.e. Dihann, Orbum and Naos, different features of the JCM model were analyzed and the method of application of "lean" measures was reviewed. Introduction of "lean" measures in these productive companies increased workers' job satisfaction. Huffy (2009) has proved that lean means such as Kaizen are quite good as long as safety, health and satisfaction of employees are concerned and they improve productivity in both the internal and external levels of the organization which in its turn increases the level of satisfaction of employees. In a research conducted by Mores (2014), it was concluded that employees' job satisfaction is improved when lean principles are executed in an organization.

As the findings of the present study indicate, organizational agility is a factor that increases employees' job satisfaction. Moghimi (2001) has expressed that agility and rapidity of the organization affect job satisfaction and attitude of employees. In addition, the results of the studies conducted by Nikpoor and Salajegheh (2010) are also indicative of a significant relationship between various potentials of agility (rapidity, flexibility, competence and responsiveness) and job satisfaction. They have stated that recently, organizational agility has become one of the factors and variables that determine the level of job satisfaction. In the field of organizational agility-leanness, the results indicate that there is a significant relationship between the two concepts. Giomara and DeCarlo (2012) have expressed that a combination of these two features can be useful and effective for reaching to a degree of responsiveness which makes the organization 'a winner in the market' because of the innovative services it provides with competitive prices. A case study has showed that a combination of these two paradigms is not only important in the outsourcing decision logic, but it is also significant in the development of each of the services of the organization (internal and external). On the other hand, there is not another research that has reviewed the ef- 
fect of simultaneous presence of leanness and agility on job satisfaction.

\section{Conclusions}

From the purpose point of view, this research is an applied research. Through identification of research variables (dimensions of agility, leanness, and job satisfaction), development of a questionnaire, collection of data from a sample of 65 people, ensuring validity and reliability, and analyzing the data. To compute the inconsistency rate and rank the job satisfaction criteria, the AHP is employed; and the fuzzy TOPSIS is used to rank the lean-agile criterions. In all the committed pairwise comparisons the consistency rate has scored less than 0.1 and ranking has been carried out. This research obtained the following results.

Results indicate ranking of the criteria also reveal the importance of the organizational factors with the most weight (0.686), and then the environmental factors with a weight of 0.126 and finally factors associated with nature of work with a weight of 0.098 . Moreover fuzzy TOPSIS demonstrates that, having the highest closeness coefficient, providing high quality services has the highest priority among the criteria. The importance of other criteria is as follows: on time services, competency, responsiveness, flexibility, speed, and waste reduction. It can be a benchmarking for researches and decision makers to apply the results of this research.

In the present study, the lean-agile approach has been examined as one of the factors affecting job satisfaction. In fact, those services that are more associated with customers must be more agile and those services that are involved with production must be leaner. In 2007, Kirshnamorti developed an organizational structure proportional with leagile. In this structure, independent variables are in fact sub-variables of agility such as the speed of responsiveness, competence and flexibility as well as sub-variables of leanness such as provision of services with higher quality, reduction of losses, timely services, etc. The dependent variables were employees' job satisfaction and their expectations. Since many individuals visit the hospital, rapid presentation of timely high-quality services can be quite important and job satisfaction can have an important impact on the realization of this matter. Therefore, the present study has aimed to examine a combination of the two factors that affect job satisfaction.

\section{References}

[1] Tahere, B., Abdorasul, J., HAmid, R. and Mohammadreza, M. (2014) Analysis of the Relationship between Organizational Justice and Job Satisfaction among the Employees of the Welfare Organization of Isfahan. Applied Sociology, 53, 72. [In Persian]

[2] Park, D.J., Eun, J., Deitz, L., et al. (2006) The Effect of Working Relationship Quality on Sales Person Performance and Job Satisfaction: Adaptive Selling Behavior in Korean Automobile Sales Representatives. Journal of Business Research, 123, 85-92.

[3] Sanjar, S. and Amin, N. (2010) Investigation of the Relationship between Organizational Agility and Job Satisfaction of the Employees of Public Organizations of 
Kerman, Iran. Management Research, No. 7, 169-184. [In Persian]

[4] Li, X., Chung, C., Goldsby, T.J. and Holsapple, C.W. (2008) A Unified Model of Supply Chain Agility: The Work-Design Perspective. International Journal of Logistics Management, 19, 408-435. https://doi.org/10.1108/09574090810919224

[5] Yang, CH. and Liu, H.M. (2012) Boosting Firm Performance via Enterprise Agility and Network Structure. Management Decision, 50, 3-30. https://doi.org/10.1108/00251741211238319

[6] Schiestel, C. (2007) Job Satisfaction among Arizona Adult Nurse Practitioners. Journal of the American Academy of Nurse Practitioners, 19, 30-34. https://doi.org/10.1111/j.1745-7599.2006.00187.x

[7] Enskär, K. (2012) Being an Expert Nurse in Pediatric Oncology Care Nurses: Descriptions in Narratives. Journal of Pediatric Oncology Nurse, 29, 151-160. https://doi.org/10.1177/1043454212446344

[8] Dawal, S.Z., Taha, Z. and Ismail, Z. (2009) Effect of Job Organization on Job Satisfaction among Shop Floor Employees in Outomotive Industries in Malasia. International Journal of Industrial Ergonomics, 39, 1-6. https://doi.org/10.1016/j.ergon.2008.06.005

[9] Matawale, C.R., Datta, S. and Mahapatra, S.S. (2013) Development of a Decision Support System for Leagility Assessment in Fuzzy Environment. Asia-Pacific International Congress on Engineering and Natural Sciences (APICENS 2013), Bangkok, 16-18 April 2013.

[10] Charles, A., Lauras, M. and Van Wassenhove, L. (2010) A Model to Define and Assess the Agility of Supply Chains: Building on Humanitarian Experience. International Journal of Physical Distribution and Logistics Management, 40, 675-692. https://doi.org/10.1108/09600031011079355

[11] Narasimhan, R., Swink, M. and SooWook, K. (2006) Disentangling Leanness and agility: An Empirical Investigation. Journal of Operation Management, 24, 440-457. https://doi.org/10.1016/j.jom.2005.11.011

[12] Evans, J.R. and Lindsay, W.M. (2008) Managing for Quality and Performance Excellence. 7th Edition, Thomson South-Western, Mason.

[13] Hafey, R.B. (2009) Lean Safety: Transforming Your Safety Culture with Lean Management. Productivity Press, New York.

[14] Holden, R.J. (2011) Lean Thinking in Emergency Departments: A Critical Review. Annals of Emergency Medicine, 57, 265-278. https://doi.org/10.1016/j.annemergmed.2010.08.001

[15] Aveta (2012) The Relationship between Employee Job Satisfaction and Business Productivity.

https://www.sixsigmaonline.org/six-sigma-training-certification-information/the-re lationship-between-employee-job-satisfaction-and-business-productivity/

[16] Barqi, S., Mahdi, Gharaei and Abolfazl (2010) Improvement and Using Willis Method to Determine the Degree of Adaptability a System with Lean Production Characteristics. Seventh International Conference of Industrial Engineering, Iran Industrial Engineering Association, Isfahan University of Technology, 6-7 October, 2010.

[17] Pool, A., Wijngaard, J. and Van der Zee, D.J. (2010) Lean Planning in the Semi-Process Industry: A Case Study. International Journal of Production Economics, 131, No. 1.

[18] Shahin, A. and Lellahgany, Z. (2011) Studying the Concept and Agility Application 
in Services. International Conference on Industrial Engineering, Tehran, 14-15 February 2012 [in Persian].

[19] Guimaraes, C.M. and de Carvalho, J.C. (2012) Leagility in Healthcare: A Start-Up Case Study. In: Modelling Value, Physica-Verlag HD, Heidelberg, 275-291. https://doi.org/10.1007/978-3-7908-2747-7_14

[20] De Haan, J., Overboom, J. and Naus, F. (2008) Discipline and Creativity in lean Production: Contradiction in Terms. Proceedings of the 13 th International Symposium on Logistics (ISL 2008): Integrating the Global Supply Chain, Nottingham University, Nottingham, 6-8 July 2008, 77-84.

[21] St. John, C.H., Cannon, A.R. and Pouder, R.W. (2001) Change Drivers in the New Millennium: Implications for Manufacturing Strategy Research. Journal of Operations Management, 19, 143-160. https://doi.org/10.1016/S0272-6963(00)00054-1

[22] Menor, L.J., Roth, A.V. and Mason, C.H. (2009) Agility in Retail Banking: A Numerical Taxonomy of Strategic Service Groups. Manufacturing and Service Operations Management, 3, 273-292.

[23] Sud-on, P., Teo, L. and Jie, F. (2011) Impact of Agile Manufacturing on Thailand Automobile Performance and Competitive Advantage. Proceedings of the 25th ANZAM Conference 2011, Wellington, New Zealand, 7-9 December 2011, 1-19.

[24] Sharpe, R. (2012) Agile University: Building the Innovation and Improvement for a Better Student Experience. Higher Education SEMINAR. Economic Summit, No. 9. http://www.elementaleadership.co.uk/

[25] Bellou, V. (2010) Organizational Culture as a Predictor of Job Satisfaction: The Role of Gender and Age. Career Development International, 15, 4-19. https://doi.org/10.1108/13620431011020862

[26] Morse, A. (2014) Evaluating the Impact of Lean on Employee Ergonomics, Safety, and Job Satisfaction in Manufacturing. Doctoral Dissertation, Faculty of the Louisiana State University and Agricultural and Mechanical College in partial fulfillment of the requirements for the degree of Master of Science in The Department of Mechanical and Industrial Engineering by Amanda Morse BS, Randolph-Macon College.

[27] Daneshvar Rouyendegh, B. (Erdebilli, B.) (2014) Thomy Eko Saputro Supplier Selection Using Integrated Fuzzy TOPSIS and MCGP, 3.

[28] Ertugrula, I. and Oztasb, T. (2014) Business Mobile-Line Selection in Turkey by Using Fuzzy TOPSIS, One of the Multi-Criteria Decision Methods. 42-43. 


\section{Questionnaire}

Questionnaires 1 and 2 have been designed for collecting information about the effect of key agile-lean factors on the job satisfaction of employees of Shiraz MIR Hospital. Some of the factors affecting the job satisfaction of these employees have been presented in the following section. Degree of significance and effectiveness of each of these factors have been specified (between 1 and 5). It is noteworthy that the score 1 is indicative of the minimum degree of effectiveness and score 5 shows the maximum degree of effectiveness of the factors.

Questionnaire no. 1. reviewing the effect of key lean-agile factors on employees' job satisfaction.

\begin{tabular}{|c|c|c|c|c|c|c|}
\hline \multirow{2}{*}{ Row } & \multirow{2}{*}{ Effective factors } & \multicolumn{5}{|c|}{ Degree of effectiveness } \\
\hline & & 1 & 2 & 3 & 4 & 5 \\
\hline 1 & $\begin{array}{l}\text { How significant is the impact of responsiveness to environmental changes on the organizational } \\
\text { factors? }\end{array}$ & & & & & \\
\hline 2 & $\begin{array}{l}\text { How significant is the impact of responsiveness to environmental changes on the environmental } \\
\text { factors? }\end{array}$ & & & & & \\
\hline 3 & $\begin{array}{l}\text { How significant is the impact of responsiveness to environmental changes on the factors associated } \\
\text { with nature of the job? }\end{array}$ & & & & & \\
\hline 4 & $\begin{array}{l}\text { How significant is the impact of competence in encountering environmental changes on the } \\
\text { organizational factors? }\end{array}$ & & & & & \\
\hline 5 & $\begin{array}{l}\text { How significant is the impact of competence in encountering environmental changes on the } \\
\text { environmental factors? }\end{array}$ & & & & & \\
\hline 6 & $\begin{array}{l}\text { How significant is the impact of competence in encountering environmental changes on the factors } \\
\text { associated with the nature of the job? }\end{array}$ & & & & & \\
\hline 7 & $\begin{array}{l}\text { How significant is the impact of flexibility in encountering environmental changes on the } \\
\text { organizational factors? }\end{array}$ & & & & & \\
\hline 8 & $\begin{array}{l}\text { How significant is the impact of flexibility in encountering environmental changes on the } \\
\text { environmental factors? }\end{array}$ & & & & & \\
\hline 9 & $\begin{array}{l}\text { How significant is the impact of flexibility in encountering environmental changes on the factors } \\
\text { associated with the nature of the job? }\end{array}$ & & & & & \\
\hline 10 & $\begin{array}{l}\text { How significant is the impact of rapidity in face of environmental changes on the organizational } \\
\text { factors? }\end{array}$ & & & & & \\
\hline 11 & $\begin{array}{l}\text { How significant is the impact of rapidity in face of environmental changes on the environmental } \\
\text { factors? }\end{array}$ & & & & & \\
\hline 12 & $\begin{array}{l}\text { How significant is the impact of rapidity in face of environmental changes on the factors associated } \\
\text { with the nature of the job? }\end{array}$ & & & & & \\
\hline 13 & How significant is the impact of providing high quality services on the organizational factors? & & & & & \\
\hline 14 & How significant is the impact of providing high quality services on the environmental factors? & & & & & \\
\hline 15 & $\begin{array}{l}\text { How significant is the impact of providing high quality services on the factors associated with the } \\
\text { nature of the job? }\end{array}$ & & & & & \\
\hline 16 & How significant is the impact of reducing losses on the organizational factors? & & & & & \\
\hline 17 & How significant is the impact of reducing losses on the environmental factors? & & & & & \\
\hline 18 & How significant is the impact of reducing losses on the factors associated with the nature of the job? & & & & & \\
\hline 19 & How significant is the impact of timely presentation of services on the organizational factors? & & & & & \\
\hline 20 & How significant is the impact of timely presentation of services on the environmental factors? & & & & & \\
\hline 21 & $\begin{array}{l}\text { How significant is the impact of timely presentation of services on the factors associated with the } \\
\text { nature of the job? }\end{array}$ & & & & & \\
\hline
\end{tabular}


Questionnaire no. 2. Reviewing the effect of key lean-agile factors on employees' job satisfaction.

\begin{tabular}{|c|c|c|c|}
\hline \multirow{2}{*}{ Key lean-agile factors } & \multicolumn{3}{|c|}{ Job satisfaction criteria } \\
\hline & Organizational factors & Environmental factors & Nature of the job \\
\hline \multicolumn{4}{|l|}{ Responsiveness } \\
\hline \multicolumn{4}{|l|}{ Competence } \\
\hline \multicolumn{4}{|l|}{ Flexibility } \\
\hline \multicolumn{4}{|l|}{ Rapidity } \\
\hline \multicolumn{4}{|l|}{ High-quality services } \\
\hline \multicolumn{4}{|l|}{ Reduction of losses } \\
\hline Timely services & & & \\
\hline
\end{tabular}

Questionnaire no. 3. Paired comparison of job satisfaction criteria.

\begin{tabular}{cccc}
\hline Job satisfaction criteria & Organizational factors & Environmental factors & Nature of the job \\
\hline Organizational factors & 1 & 1 & 1 \\
Environmental factors & & & 1 \\
Nature of the job & & \\
\hline
\end{tabular}

The following questionnaire has been designed for collecting information about the ranking of job satisfaction criteria of the employees of Shiraz MIR Hospital. Some of the factors affecting the job satisfaction of these employees have been presented in the following section. Degree of significance and effectiveness of each of these factors have been specified (between 1 and 5). It is noteworthy that the score 1 is indicative of the minimum degree of effectiveness and score 5 shows the maximum degree of effectiveness of the factors. 